\title{
Leveraging collective intelligence: How to design and manage crowd-based business models
}

DOI:

10.1016/j.bushor.2016.11.008

Document Version

Accepted author manuscript

Link to publication record in Manchester Research Explorer

\section{Citation for published version (APA):}

Taeuscher, K. (2017). Leveraging collective intelligence: How to design and manage crowd-based business models. Business Horizons, 60(2), 237-245. https://doi.org/10.1016/j.bushor.2016.11.008

\section{Published in:}

Business Horizons

\section{Citing this paper}

Please note that where the full-text provided on Manchester Research Explorer is the Author Accepted Manuscript or Proof version this may differ from the final Published version. If citing, it is advised that you check and use the publisher's definitive version.

\section{General rights}

Copyright and moral rights for the publications made accessible in the Research Explorer are retained by the authors and/or other copyright owners and it is a condition of accessing publications that users recognise and abide by the legal requirements associated with these rights.

\section{Takedown policy}

If you believe that this document breaches copyright please refer to the University of Manchester's Takedown Procedures [http://man.ac.uk/04Y6Bo] or contact uml.scholarlycommunications@manchester.ac.uk providing relevant details, so we can investigate your claim.

\section{OPEN ACCESS}




\title{
Leveraging Collective Intelligence: How to Design and Manage Crowd-Based Business Models
}

\author{
Karl Täuscher ${ }^{1,2}$
}

Täuscher, Karl (2016). Leveraging collective intelligence: How to design and manage crowd-based business models. Business Horizons, 60(2), 237-245.

Publisher's version is available at: $\underline{\text { https://www.sciencedirect.com/science/article/pii/S0007681316301306 }}$

DOI: 10.1016/j.bushor.2016.11.008

\footnotetext{
${ }^{1}$ Fraunhofer Center for International Management and Knowledge Economy; Business Models: Engineering and Innovation; Neumarkt 9-19, 04109 Leipzig, Germany

${ }^{2}$ University of Leipzig, Department of Innovation Management and Innovation Economics. Grimmaische Straße 12, 04109 Leipzig, Germany
} 


\begin{abstract}
Advances in digital technologies have increased the possibilities for outsourcing business activities to crowds of independent contributors. Using the collective intelligence of a crowd opens a new range of business opportunities. In fact, crowdsourcing has led to the emergence of entirely new business models. Such crowd-based business models (CBBMs) can lead to an important competitive advantage, but simultaneously present new challenges to entrepreneurs and executives. This article identifies and discusses three key challenges in designing and managing CBBMs: determining the crowd's value to the firm, how to create superior value for the crowd, and how to effectively capture value from the crowd. Building on the crowd capital perspective and an analysis of the tactics and practices of successful CBBMs, this article offers propositions on how to overcome these challenges and effectively manage such business models. The identified practices can inspire decision makers when designing innovative CBBMs for their industries. Finally, the article presents a framework with the key decisions and tactics for effectively managing CBBMs.
\end{abstract}

Key Words: Crowd-based business models, Crowdsourcing, Value co-creation, Crowd capital, Collective intelligence 


\section{Crowds as Value Creators: New Possibilities}

Practitioners and researchers have increasingly identified crowdsourcing as a viable strategy to gather creative ideas and solutions, make decisions and outsource small tasks (Prpić, Shukla, Kietzmann, \& McCarthy, 2015). So far, the focus has been primarily on how firms can capture the aggregated 'wisdom of the crowd' (Surowiecki, 2005) for their business challenges. Over the last years, however, firms from different industries have started to develop new business models that fundamentally integrate crowds in their value creation logic. The emergence of these crowdbased business models is both driven by advances in internet-based technologies (Kietzmann, Hermkens, McCarthy, \& Silvestre, 2011) as well as a shift in the role of consumers towards becoming so-called 'prosumers' (Ritzer, 2014).

Crowd-based business models (CBBMs) are generally characterized by (a) the integration of contributors from outside the traditional firm boundaries, (b) the exploitation of technologies such as digital peer-to-peer platforms, and (c) the transfer of value creating activities to a crowd (Kohler, 2015). This requires the firm to open certain resources and processes to external contributors, often resulting in a strong interaction with these contributors and their resources. The activity of these contributors can range from conducting micro-tasks to creating and delivering entire products and services to the firm's customers. In that sense, CBBMs place even more importance on the crowd than traditional forms of crowdsourcing (Kohler, 2015).

Due to their inherent value co-creation with crowds, CBBMs can lead to novel and superior value propositions. Wikipedia is a case in point. Originally considered a lower-cost and lower-quality alternative to established encyclopedias, the founding team has built effective systems to engage and use a crowd of content contributors to constantly review and update its articles. As such, the platform had soon developed into the most comprehensive and up-to-date source of information. 
The rise of Wikipedia provided a first confirmation for the power of collective intelligence for crowd-based value creation. Lévy (1997, p. 13) defines collective intelligence as "a form of universally distributed intelligence, constantly enhanced, coordinated in real time, and resulting in the effective mobilization of skills. [...] The basis and goal of collective intelligence is mutual recognition and enrichment of individuals rather than the cult of fetishized or hypostatized communities." In simple terms, the concept of collective intelligence builds on the idea that "[n]o one knows everything, everyone knows something" (Lévy, 1997, p. 13). As Wikipedia and other examples have shown, there exists a large potential for organizations to leverage the intelligence of individuals outside their boundaries. Or, as Sun Microsystem's co-founder Bill Joy aptly formulated in what is now known as 'Joy's Law': "No matter who you are, most of the smartest people work for someone else" (Lakhani \& Panetta, 2007, p. 2).

Several new ventures have sensed this opportunity and developed business models that capitalize on individual contributors to create and/or deliver value based on their specific expertise. Take the example of Skillshare, a technology venture founded in 2011. Skillshare provides a digital platform that offers thousands of live classes on a broad variety of topics. Yet, instead of employees teaching these classes, the platform uses a crowd of independent experts to teach classes related to their expertise and interests. To gain access to the entire range of classes, individual learners pay a monthly fee to the firm. Convinced by the variety and relevance of the crowd-created content, businesses like Twitter or Adobe have adopted the service to train their employees. As a reward of their contributions, Skillshare pays a royalty to its crowd members depending on the number of students they can attract to their live classes. Such business models fulfill the original definition of crowdsourcing as "outsourcing of an organizational function to a strategically defined network of human and non-human actors in the form of an open call" 
(Kietzmann, 2017, p. 3). Firms building a CBBM further have to integrate the crowd into the firm's general logic of creating value and transforming this value into revenues and profits. Business models generally raise and answer questions about how an organization creates and delivers value to its customers and transforms this value into revenues and profits (Teece, 2010). Developing a CBBM requires additional answers to the following three questions: What is the crowd's value to the firm? How to create value for the crowd? How to capture value from the crowd? So far, there is not much knowledge available on how firms approach these questions and solve specific challenges to successfully develop and manage CBBMs. Hence, this article aims to support managers in designing and managing crowd-based business models. Particularly, the article answers three questions:

- How to assess the crowd's value for the firm?

- How can a firm create superior value for the crowd?

- How can a firm capture more value from the crowd?

Each of the following three sections addresses one of the questions to identify the relevant decision criteria and strategies of managers in successfully designing and running CBBMs. Section 2 presents criteria on which executives can determine the value of a crowd for their business and decide whether they should attract more individuals to their crowd. Section 3 illustrates business practices to create superior value for crowds that allow firms to compete with other crowd-based businesses. Section 4 discusses tactics to capture more value from the crowd by effectively leveraging their potential. Finally, section 5 presents an integrative framework that summarizes the main insights for successfully designing and managing CBBMs. 


\section{Measure to Manage: What is the Crowd's Value to the Firm?}

While CBBMs can be highly effective, the decision for adapting such a business model needs to be complemented with a thorough analysis of the crowd's potential value to the firm. Moreover, managing a CBBM requires an understanding about the optimal size of the firm's crowd. To do so, managers of CBBMs need to decide whether a further increase in the crowd's size will lead to more value creation to their customers and ultimately more value to the firm. The crowd's value to the firm can be represented with the concept of crowd capital as introduced by Prpić and colleagues (2015). They define crowd capital as the "organizational resources acquired through crowdsourcing" (p. 80). For the management of CBBMs, it is of particular importance to assess the firm's net value of increasing the crowd size. This can be considered as the marginal crowd capital. In many cases, the relationship between the size of the crowd and the crowd capital can be described as an inverted U-shaped curve. In other words, the firm will only gain a positive marginal crowd value until a certain optimum point. At different stages of the firm's development, managers have to decide whether to unconditionally invite individuals to become contributors or to limit and/or preselect access of contributors to their platform. The decision generally depends on six key criteria:

Strategic objectives: A key factor in determining the size of the crowd are the firm's strategic objectives. A growth-oriented venture aiming to rapidly grow their content supply can greatly benefit from attracting as many content creators as possible. Strategy scholars have shown that firms that operate in markets with strong positive network effects can create a competitive advantage through differentiation by building a larger contributor network than their competitors (Eisenmann, Parker, \& van Alstyne, 2006). Contrary, a company that intends to pursue a 
differentiation strategy by developing a library of high quality content for a small niche market will prioritize quality over quantity and thus benefits from limiting access to its platform.

Cost of crowd creation: Creating a crowd requires a deliberate acquisition process. Particularly for more specialized tasks, firms need to approach the task of crowd creation in a similar way as their customer acquisition process. Access to potential crowd members is limited and in demand. Thus, to compete in the market for members of a specific crowd, firms have to actively acquire them through marketing activities (Choi \& Lee, 2016). The acquisition costs will generally be higher, the more specialized the crowd tasks are. However, the cost can change significantly over time with changes in the supply and demand of a particular type of crowd. Besides, established platforms can often decrease the costs of contributor acquisition over time due to strong branding, scale economies in acquisition strategies, and word-of-mouth dynamics from existing contributors. Hence, managers are encouraged to measure their cost of acquiring additional crowd members continuously.

Distribution of value creation among contributors: Not all crowd members create equal value to the firm. In large crowds, the Pareto rule of 80-20 often finds empiric evidence. For the crowdsourcing context, the heuristic suggests that twenty percent of contributors often create eighty percent of the value. For instance, a study on crowdsourced science projects - involving volunteers for 'citizen science' - reports that the only a small number of individuals was responsible for the majority of contributions and most participants did not contribute in any significant way (Franzoni \& Sauermann, 2014). Yet, the value of a crowd member's contribution quality can change over time. On the one hand, pioneering contributors show high commitment to the platform and become more experienced over time. These contributors then sometimes create a series of high value contributions. On the other hand, empiric insights in crowd-based 
innovation communities have shown that crowd members tend to contribute less valuable ideas over time because they are often tied in their creative thinking to their successful contributions from the past (Bayus, 2013). To assess the size of these opposing effects, managers should monitor the net contribution of different crowd cohorts over time. This will determine whether the firm should keep on acquiring new crowd members.

Risks from crowd: Managing a large crowd of contributors is not without risks. Wilson, Robson, \& Botha (2017) studying failed crowdsourcing projects to identify associated risks. In CBBMs, the crowd can potentially become an even bigger risk to the viability of the entire business model. For instance, manipulative crowd behavior has been observed in crowdsourced contests in which public figures leverage their audience to commonly support a prank. Comedian Stephen Colbert, for instance, used his television presence to motivate his audience to vote for the name 'Colbert' in a crowd-based competition initiated by NASA for naming a new space module. With more than 200,000 votes, the name won the competition by far. Deciding to use a second placed name form the competition, NASA came under strong public criticism (Sample, 2009). In standardized micro-tasks, crowd votes, idea and solution contests, the potential damage is limited. Yet, in business models where contributors are responsible for creating and delivering value directly to consumers, every crowd member can sustainably harm the attractiveness of the entire model. For instance, some companies have been strongly criticized after few crowd members had published copied or poorly researched content. Hence, managers need to critically assess how much control they want to maintain over the work of the crowd. Then, they should frequently monitor the amount of customer complaints to decide whether an increase in crowd size can harm the model or should only come with stronger control and curation mechanisms. 
Direct network effects: Additional crowd members often influence the platform's value for the existing crowd. Some studies have empirically revealed a negative externality of increased network size on existing crowd members (Boudreau \& Jeppesen, 2015). The same-side or direct network effects are particularly negative if supply is homogenous and additional content leads to the substitution of existing content (Belleflamme \& Toulemonde, 2009). This dynamic has been described as crowding-out and identified as a key barrier to further innovation incentives (Boudreau, 2012). The effect is particularly high in platforms that incentivize crowd participation by sharing part of the firm's revenues with its contributors according to their contribution's popularity. As such, managers should measure the satisfaction, engagement, and performance of its existing crowd members over time to detect dissatisfaction from increased competition between crowd members. The amount of direct network effects is determined, among others, by (1) the heterogeneity of demand from customers, (2) whether the contributions are geographically limited, and (3) whether contributors compete for a scarce resource such as attention or money.

Indirect network effects: Many CBBMs effectively represent two-sided business models that connect the crowd as suppliers directly with the firm's customers. Thus, customer satisfaction with the firm's offering depends directly on the size and quality of the crowd - an effect known as cross-side or indirect network effects (Rochet \& Tirole, 2003). A recent study on unpaid contributors in the context of multi-player gaming concludes that the attraction of additional contributors increased the motivation for players to engage in the game. Since an increase in contributors simultaneously led to less value for the existing crowd of contributors, the effects neutralized each other (Boudreau \& Jeppesen, 2015). Generally, the attractiveness of an expertise marketplace such as Skillshare depends on the availability of sufficient crowd members at any time to fulfill the demand at any time. In those business models where crowd members produce 
lasting content such as entire apps or online courses, additional contributors will generally increase the value for customers if:

- quality levels remain at least equal,

- the additional course does not simply substitute an existing one,

- consumers are not 'pressured' by the large selection to consume excessively

- and consumers can effectively search the platform for specific niche products (CasadesusMasanell \& Hałaburda, 2014).

To date, measuring the indirect network effects has proven difficult in practice. Managers of successful CBBMs use rigorous data gathering and experimentation to understand the link between the size of the crowd and the satisfaction of its customers with the total offering. Managers should integrate the six criteria into a management dashboard and frequently review changes in these metrics.

\section{Four Practices for Creating Superior Value for the Crowd}

According to the crowd capital perspective, firms are benefiting from crowdsourcing when they successfully build the capabilities for acquiring and assimilating crowd members and harnessing crowd capital (Prpić et al., 2015). Similarly, building a sustainable CBBM requires mechanisms that attract and engage crowd members to contribute long-term to the firm. Being in a competitive situation for crowds, companies must develop a clear value proposition to attract crowd members to participate (Kohler, 2015). Successful CBBMs tend to combine four practices when developing and delivering a value proposition to the crowd: identification of crowd members' contribution motives, development of design toolkits, mechanisms for the development of crowd members' capabilities, and the creation of value between contributors. 


\subsection{Identifying contribution motives of crowd members}

Firms with CBBMs deliberately analyze the key motivation of crowd members to determine a suitable value proposition. Existing research has reinforced the idea that crowdsourcing platforms can attract and engage the crowd through extrinsic motivations such as an additional income opportunity (Frey, Lüthje, \& Haag, 2011). Empirical evidence suggests that a more nuanced consideration can unlock great potential for attracting and engaging crowds in different business models (Kuznetsov, 2006; Lakhani \& Hippel, 2003). For instance, contributing training content can serve educators as a means towards building a personal brand and a promotion channel for other products or consulting services. Likewise, contributors are driven by a large array of social or emotional motivations, ranging from the pure joy of contributing (Von Ahn \& Dabbish, 2004), to expectations of reciprocity (Andreoni, 2007), recognition (Jeppesen \& Frederiksen, 2006) and pride from an enhanced social image (Ellingsen and Johannesson, 2008). As a consequence, managers need to understand the actual motives of their crowd for contributing. Identifying the core motives further helps prioritizing the related attributes of the value proposition. For instance, the blocking of Wikipedia in Mainland China led to a reduced readership of Chinese articles and thus less impact opportunity for contributors. As a consequence of the decreased audience, engagement of Chinese contributors from other parts of the world significantly decreased (Zhang \& Zhu, 2011). Hence, introducing a paywall to Wikipedia would likely lead to strongly reduced engagement of its contributors. In business models that share revenues with crowds, contributors are often focused on revenue opportunities and individual performance. Managers should therefore identify the key value attributes they offer to their crowd members and develop ideas for strengthening the value proposition around these motives. 


\subsection{Developing design toolkits for the crowd}

Successful CBBMs provide design toolkits to their crowds that allow a superior experience in creating the content, task or service. The proposition of innovation toolkits has been suggested by von Hippel and Katz (2002) in the context of user innovation: "Toolkits for user innovation are coordinated sets of 'user-friendly' design tools that enable users to develop new product innovations for themselves. The toolkits are not general purpose. Rather, they are specific to the design challenges of a specific field or sub field" (p. 2). Udemy, a platform offering a variety of online courses that are entirely created by a crowd of more than 20,000 , was initially confronted with relatively high abandonment rates of contributors who struggled to create high-quality courses due to a lack of pedagogical and technical know-how. As a consequence, the company developed a design toolkit based on latest pedagogical findings that automatically guides course creators through the process of planning, developing and implementing engaging multi-media material. Besides, the platform provides contributors with a drag-and-drop structure to arrange their modular videos, assessments or text documents, which allows them to create their courses more efficiently. Attractive toolkits can serve as a differentiating factor among competing crowdbased business models by increasing the contributor experience and enhancing their impact.

\subsection{Fostering development of crowd members' capabilities}

CBBMs can create long-term relationships with their crowd if they allow them to grow their skill set by using the platform. Many of the firms therefore provide contributors with data-based feedback on their performance. Idea and innovation contests have proven most effective if contributors have high transparency over the criteria for winning such a contest (Huang \& Fu, 2013). Similarly, crowd-based learning platforms can create value for their contributors if they allow them to receive customer feedback on the quality of their contribution. CBBMs often 
provide personalized dashboards and analytics tools to allow contributors to understand the engagement of customers with their contributions. Analytics solutions can help contributors learn about their work's quality - and lead to continuous improvement (Hippel \& Katz, 2002). For instance, Udemy integrates a survey in their courses in which students assess the quality of both the teacher and course material. Combined with data on students' actual engagement with a contributors' material and presented in a visually attractive dashboard, contributors receive ongoing feedback about the quality of their contributions. Even contributors of micro-tasks such as translation services increasingly receive peer reviews that allow them to strengthen their skills. Managers should identify and develop effective tools to help their contributors receive timely feedback on their contributions. Such feedback mechanisms furthermore function as a quality control for the platform's content and provide a reputation mechanism that increases the contributor's perceived cost of switching to a competing platform.

\subsection{Generating value between crowd members}

Successful CBBMs deliberately support and incentivize contributors in generating value for each other. As seen above, network externalities between members of a contributing crowd are often negative. New contributors might crowd out or substitute existing ones. Especially in paid crowd tasks, members compete for a limited market. Firms can overcome this negative externality by creating platform functions with positive externalities. Most prominently, CBBMs offer actively managed online communities for crowd members. Online teachers at Skillshare, for instance, can exchange ideas and best practices on how to structure lectures or how to deal with difficult students over these community platforms. Besides, the firm's communication towards the community of contributors' plays an important role in whether they appreciate further members joining the crowd. Generally, a strong feeling of a social mission worth pursuing, a feeling of 
shared engagement against a competing platform, or individual benefits from an increased network of contributors will create positive direct network effects. Some forms of crowdsourcing - such as innovation contests or other competitive markets - inevitably lead to negative network effects between contributors. Yet, research has shown that contributors are more likely to join a contest despite a large crowd when they perceive the underlying procedure as fair and transparent (Franke, Keinz, \& Klausberger, 2013). As a consequence, managers aiming to increase the value for their crowd can use one or more of the four practices to provide more value for their crowd. The implementation of such mechanisms should be decided based upon a series of experiments with a sample of contributors.

\section{Five Tactics for Capturing More Value from the Crowd}

The third managerial challenge consists in actually capturing the value from the crowd's contributions. This relates to the third step in the crowd capital framework: harnessing the crowd capital. The analysis of the presented CBBMs suggests that they use common mechanisms and practices to capture more value from their crowds: increasing complementarity between crowd contributions, turning crowd members into firm ambassadors, incentivizing crowd members to act entrepreneurial, actively managing crowd risks and locking-in of high-value crowd members.

\subsection{Create complementarities between crowd contributions}

A first tactic to capture more value from a crowd is to ensure the complementarity of different contributions. While this is relatively easy for votes, ideas, and smaller solutions, crowds in CBBMs compete in many cases for customer attention, influence and revenues. Lists that rank contributions or crowd members by popularity tend to favor few choices that become even more popular over time. Yet, recent advances in search technologies and machine learning-based 
recommendation systems have enabled the co-existence of a variety of specialized supply (Weld et al., 2012).

\subsection{Turn crowd members into firm ambassadors}

Firms can capture more value from their developed crowd by transforming contributors into firm ambassadors. CBBMs that share revenues with the crowd provide incentives for contributors to promote their own content and therefore - at least indirectly - the firm's brand and platform. Platforms that build on more intrinsic motivations can capture additional value from their contributors when they motivate and enable them to recommend the company among their network to 'spread the word' about the platform's social mission or their own contributions. Managers can utilize proven strategies and tools from marketing to enhance the contributors' rate of recommendations. For instance, Udemy has developed a sophisticated system of financial rewards if contributors acquire new learners for their courses.

\subsection{Foster entrepreneurial behavior of contributors}

Traditional crowdsourcing projects such as idea competitions and crowd votes build on the concept of wisdom of the crowd. A large crowd will collaboratively diverge towards a stronger solution than individual actors (Chiu, Liang, \& Turban, 2014) - an idea generally credited to Aristotle (Ober, 2013) (Ober,É. In the area of content creation, diversity of contributions is generally more important than convergence towards a common solution. In other words, platforms can capture more value if the crowd creates a broad set of content. Entrepreneurs and managers can build mechanisms that incentivize contributors to actively search for market gaps and help them recognize and exploit untapped opportunities (Smith, Manesh, \& Alshaikh, 2013). One instrument are data-based analytics tools that help contributors gain a better understanding of the existing supply created by the crowd, areas of high demand, and supply gaps. These data can 
further be used to develop a time-dependent pricing system that allows crowd members to recognize times of high demand. For instance, the ridesharing service Uber has developed a sophisticated model of price surges that incentivizes the crowd of drivers to start driving when the demand temporarily exceeds the supply of available drivers in a particular area. The underlying mechanism of these instruments is to provide transparency about the market demand and guide contributors to high-impact areas of value creation.

\subsection{Manage risks of crowd behavior}

Managers can reduce the risks from opportunistic and damaging behavior of crowd members through active governance and control, review systems, and the creation of incentives for desired behavior. To decrease the odds of unintended crowd behavior, successful CBBMs provide a code of conduct and guidelines for participating on their platform. Mistreating the code of conduct is usually sanctioned with increasing levels of punishment such as deactivation of one's access to the platform. To detect inappropriate content, hidden advertisements to third party offerings in crowd contributions would require a complete review of all crowd activities. This is practically impossible in services such as Skillshare in which crowd members interact directly with customers. Thus, platform providers rely on customers providing feedback on such issues. To make use of the customers' feedback, managers can develop an early-warning system that automatically checks the content for copyright infringements and signals unusual patterns of customer dissatisfaction or abandonment of the service.

\subsection{Lock-in of high-value crowd members}

Firms can capture more value from a crowd by increasing the duration of the relationships with their high-value crowd members. As discussed above, a relatively small fraction of crowd contributors creates a large amount of the value. Here, the challenge consists in (a) identifying 
these high-value contributors and (b) designing mechanisms to strengthen the relationship with these contributors and (c) appropriating the contribution's value itself. The level of potential appropriation of crowd contribution depends primarily on the type of the CBBM. In content marketplaces like Udemy, the contributor often maintains intellectual property rights and can decide to withdraw his contribution at any time. In crowd-based services like Skillshare, the risk of losing crowd capital is even higher since it depends on the contributors' continuous motivation to contribute. At the same time, such models provide high incentives for contributors to frequently improve or renew their content. Thus, managers of such business models are confronted with the challenge of locking-in successful contributors. To do so, they should develop rewarding incentives for popular contributors for sustained engagement. For instance, elements and principles from game design - discussed under the term Gamification - are commonly used tools to sustainably motivate stakeholders to engage with a firm's platform (Robson, Plangger, Kietzmann, McCarthy, \& Pitt, 2016). Early empirical evidence suggests that game mechanics like leaderboards, points and badges are effective tools to complement crowdsourcing tasks (Morschheuser, Hamari, \& Koivisto, 2016; Robson, Plangger, Kietzmann, McCarthy, \& Pitt, 2015). Besides creating design elements to lock-in contributors, managers should continuously maintain an open conversation with the crowd to understand their potential sources of dissatisfaction. Finally, actively measuring the level of engagement and retention of successful crowd members can serve as an early warning system for a potential decline in crowd capital due to crowd member dissatisfaction or the emergence of competing platforms targeting the same crowd. 


\section{$5 \quad$ Final Thoughts}

CBBMs extend the usefulness of crowdsourcing by building an entire value logic around contributors from a crowd that directly influence the customer experience. As such, their logic goes beyond the idea of an aggregated 'wisdom of the crowd' by acknowledging the individual skills and expertise of every crowd member. This research has advanced the understanding of crowd-based business models, aiming to sensitize managers for a more analytical approach to designing and managing CBBMs. While crowds have been identified as highly promising sources of value co-creation, managers need to analyze the crowd's actual value to their firm on a regular basis. As argued, a larger crowd is not necessarily increasing the value for the firm's customers. In fact, a truly 'open call' to individual contributors can decrease the customers' experience and yield negative externalities on other contributors. The article has therefore identified relevant criteria and decisions that correspond to the challenges of crowd acquisition, crowd capability development, and crowd capital harnessing. These decisions relate to three specific elements of crowd-based business models.

[Insert Figure 1 about here]

Figure 1 summarizes the identified criteria and practices that influence the firm's value from crowd creation and engagement ('crowd value') as well as the practices for creating superior value for the crowd and effectively capturing value from the crowd. The outlined criteria can support executives in designing novel CBBMs and making informed decisions when managing them. The framework further allows identifying how established methods and tools - such as design toolkits - can support the development of crowd capital in these business models. Most importantly, the article can be seen as a call for a more deliberate approach to effectively leveraging the collective intelligence with complementary business models. 


\section{References}

Andreoni, J. (2007). Giving gifts to groups: How altruism depends on the number of recipients. Journal of Public Economics, 91(9), 1731-1749. doi:10.1016/j.jpubeco.2007.06.002

Bayus, B. L. (2013). Crowdsourcing New Product Ideas over Time: An Analysis of the Dell IdeaStorm Community. Management Science, 59(1), 226-244. doi:10.1287/mnsc.1120.1599

Belleflamme, P., \& Toulemonde, E. (2009). Negative intra-group externalities in two-sided markets. International Economic Review, 50(1), 245-272. doi:10.1111/j.1468-2354.2008.00529.x

Boudreau, K. J. (2012). Let a Thousand Flowers Bloom? An Early Look at Large Numbers of Software App Developers and Patterns of Innovation. Organization Science, 23(5), 1409-1427. doi:10.1287/orsc.1110.0678

Boudreau, K. J., \& Jeppesen, L. B. (2015). Unpaid crowd complementors: The platform network effect mirage. Strategic Management Journal, 36(12), 1761-1777. doi:10.1002/smj.2324

Casadesus-Masanell, R., \& Hałaburda, H. (2014). When Does a Platform Create Value by Limiting Choice? Journal of Economics \& Management Strategy, 23(2), 259-293. doi:10.1111/jems.12052

Chiu, C.-M., Liang, T.-P., \& Turban, E. (2014). What can crowdsourcing do for decision support? Decision Support Systems, 65, 40-49. doi:10.1016/j.dss.2014.05.010

Choi, J. H., \& Lee, J. S. (2016). Online social networks for crowdsourced multimedia-involved behavioral testing: An empirical study. Frontiers in Psychology, 6(JAN). doi:10.3389/fpsyg.2015.01991

Eisenmann, T., Parker, G., \& van Alstyne, M. W. (2006). Strategies for two-sided markets. Harvard Business Review, 84(10).

Franke, N., Keinz, P., \& Klausberger, K. (2013). "Does This Sound Like a Fair Deal?": Antecedents and Consequences of Fairness Expectations in the Individual's Decision to Participate in Firm Innovation. Organization Science, 24(5), 1495-1516. doi:10.1287/orsc.1120.0794

Franzoni, C., \& Sauermann, H. (2014). Crowd science: The organization of scientific research in open collaborative projects. Research Policy, 43(1), 1-20. doi:10.1016/j.respol.2013.07.005

Frey, K., Lüthje, C., \& Haag, S. (2011). Whom Should Firms Attract to Open Innovation Platforms? The Role of Knowledge Diversity and Motivation. Long Range Planning, 44(5-6), 397-420. doi:10.1016/j.Irp.2011.09.006

Hippel, E. v., \& Katz, R. (2002). Shifting Innovation to Users via Toolkits. Management Science, 48(7), 821-833. doi:10.1287/mnsc.48.7.821.2817

Huang, S.-W., \& Fu, W.-T. (2013). Don't hide in the crowd!: Increasing social transparency between peer workers improves crowdsourcing outcomes. In ACM (Ed.), Proceedings of the SIGCHI Conference on Human Factors in Computing Systems, April 27-May 02, 2013, Paris, France. (pp. 621-630). New York, NY, USA: ACM. doi:10.1145/2470654.2470743

Jeppesen, L. B., \& Frederiksen, L. (2006). Why Do Users Contribute to Firm-Hosted User Communities? The Case of Computer-Controlled Music Instruments. Organization Science, 17(1), 45-63. doi:10.1287/orsc.1050.0156

Kietzmann, J. H. (2017). Crowdsourcing Revisited. Business Horizons, 60(2). 
Kietzmann, J. H., Hermkens, K., McCarthy, I. P., \& Silvestre, B. S. (2011). Social media? Get serious! Understanding the functional building blocks of social media, 54(3), 241-251. doi:10.1016/j.bushor.2011.01.005

Kohler, T. (2015). Crowdsourcing-Based Business Models: How to Create and Capture Value. California Management Review, 57(4), 63-84. doi:10.1525/cmr.2015.57.4.63

Kuznetsov, S. (2006). Motivations of contributors to Wikipedia. ACM SIGCAS Computers and Society, 36(2), 1-es. doi:10.1145/1215942.1215943

Lakhani, K. R., \& Hippel, E. v. (2003). How open source software works: "free" user-to-user assistance. Research Policy, 32(6), 923-943. doi:10.1016/S0048-7333(02)00095-1

Lakhani, K. R. \& Panetta, J. A. (2007). The Principles of Distributed Innovation.

Lévy, P. (1997). Collective intelligence: Mankind's emerging world in cyberspace. New York: Plenum Trade. Retrieved from http://www.h-net.org/review/hrev-a0a4k6-aa

Morschheuser, B., Hamari, J., \& Koivisto, J. (2016). Gamification in Crowdsourcing: A Review. In 49th Hawaii International Conference 2016 (pp. 4375-4384). doi:10.1109/HICSS.2016.543

Ober, J. (2013). Democracy's Wisdom: An Aristotelian Middle Way for Collective Judgment. American Political Science Review, 107(01), 104-122. doi:10.1017/S0003055412000627

Prpić, J., Shukla, P. P., Kietzmann, J. H., \& McCarthy, I. P. (2015). How to work a crowd: Developing crowd capital through crowdsourcing. Business Horizons, 58(1), 77-85. doi:10.1016/j.bushor.2014.09.005

Ritzer, G. (2014). Prosumption: Evolution, revolution, or eternal return of the same? Journal of Consumer Culture, 14(1), 3-24. doi:10.1177/1469540513509641

Robson, K., Plangger, K., Kietzmann, J. H., McCarthy, I., \& Pitt, L. (2015). Is it all a game?: Understanding the principles of gamification. Business Horizons, 58(4), 411-420.

Robson, K., Plangger, K., Kietzmann, J. H., McCarthy, I., \& Pitt, L. (2016). Game on: Engaging customers and employees through gamification. Business Horizons, 59(1), 29-36.

Rochet, J.-C., \& Tirole, J. (2003). Platform Competition in Two-Sided Markets. Journal of the European Economic Association, 1(4), 990-1029. doi:10.1162/154247603322493212

Sample, I. (2009). Colbert, we have a problem. The Guardian. Retrieved from https://www.theguardian.com/science/blog/2009/apr/15/nasa-names-space-station-module-oncolbert-report

Smith, D., Manesh, M. M. G., \& Alshaikh, A. (2013). How Can Entrepreneurs Motivate Crowdsourcing Participants? Technology Innovation Management Review, 3(2). Retrieved from http://timreview.ca/sites/default/files/article_PDF/Smith_et_al_TIMReview_February2013.pdf

Surowiecki, J. (2005). The wisdom of crowds: why the many are smarter than the few and how collective wisdom shapes business, economies, societies and nations (1st ed.). New York NY: Anchor Books.

Teece, D. J. (2010). Business Models, Business Strategy and Innovation. Long Range Planning , 43(2-3), 172-194.

Von Ahn, L., \& Dabbish, L. (2004). Labeling images with a computer game. Conference on Human Factors in Computing Systems - Proceedings, 319-326. 
Weld, D. S., Adar, E., Chilton, L., Hoffmann, R., Horvitz, E., Koch, M.,. . Mausam, M. (2012, July). Personalized Online Education - A Crowdsourcing Challenge. In AAAI (Ed.), Workshops at the Twenty-Sixth AAAI Conference on Artificial Intelligence. Retrieved from http://www.aaai.org/ocs/index.php/WS/AAAIW12/paper/download/5306/5620

Wilson, M., Robson, K., \& Botha, E. (2017). The Dark Side of Crowdsourcing: Lessons from Failed Crowdsourcing Campaigns. Business Horizons, 60(2).

Zhang, X., \& Zhu, F. (2011). Group Size and Incentives to Contribute: A Natural Experiment at Chinese

Wikipedia. American Economic Review, 101(4), 1601-1615. doi:10.1257/aer.101.4.1601

Figure 1. Designing and managing successful CBBMs

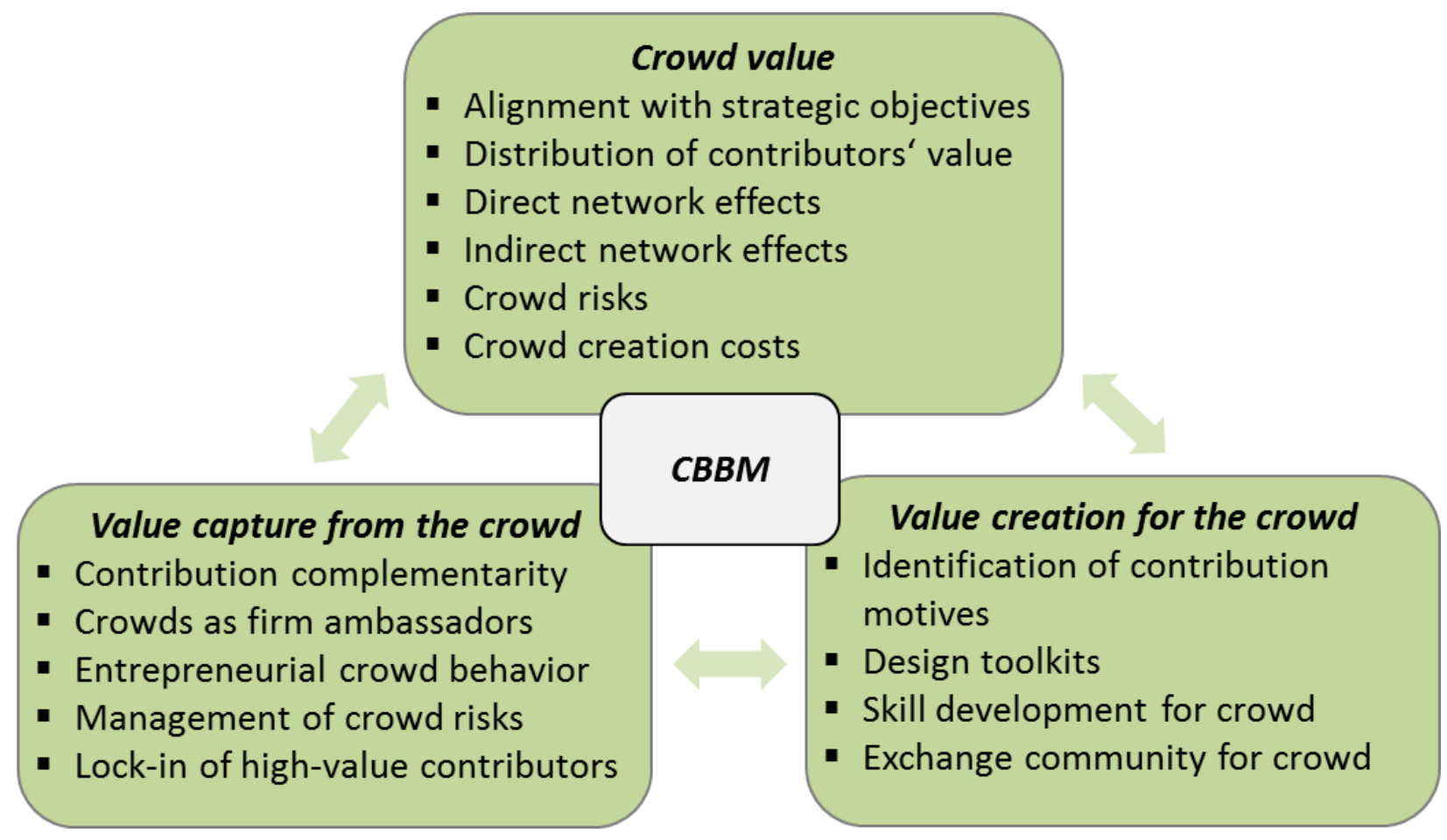

